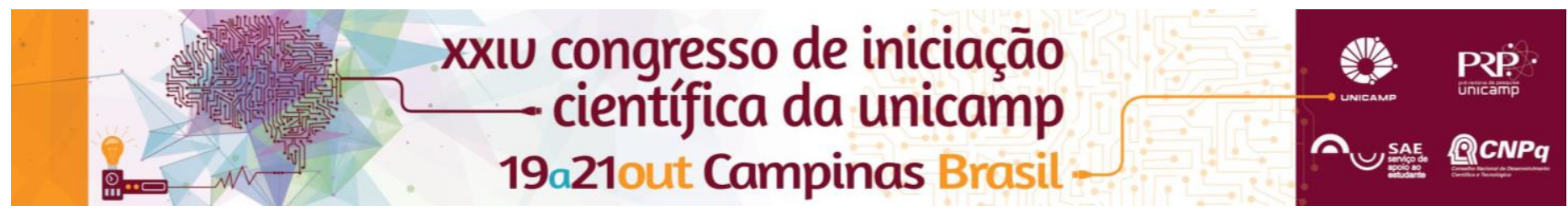

\title{
Avaliação das propriedades dinâmicas de pontes em escala reduzida utilizando a técnica de correlação de imagens digitais
}

\section{Gustavo Henrique Siqueira, Leandro Mouta Trautwein, Renata Vilar Yamao*}

\section{Resumo}

A pesquisa foi utilizada para a determinação das frequências naturais e dos modos próprios de vibração de uma ponte em alumínio. Para isso, a técnica de correlação de imagens digitais (CID) para a análise de estruturas foi utilizada, especificamente para a determinação do campo de deslocamentos sem a necessidade de contato com a estrutura.

Palavras-chave:

Correlação de Imagens Digitais, Propriedades Dinâmicas, Ponte de Alumínio

\section{Introdução}

A pesquisa consistiu na aquisição de imagens de uma ponte de alumínio sendo excitada durante um determinado intervalo de tempo. Utilizando-se o software Ncorr, foi possível traçar a trajetória do campo de deslocamentos totais destes pontos. Esses dados foram utilizados para determinação da frequência e do respectivo modo fundamental de vibração da estrutura. Para avaliar a eficiência da técnica, foi realizada uma modelagem numérica da ponte no SAP2000 e, desse modo, além de comparar os resultados obtidos pela correlação de imagens digitais (CID) ${ }^{1}$, também foi possível identificar que o modo fundamental da estrutura ocorre transversalmente.

\section{Resultados e Discussão}

Foram realizados ensaios de vibração ambiente de uma ponte de alumínio em escala reduzida (Figura 1) em que se coletaram fotografias digitais que, posteriormente, foram usadas para obtenção dos campos totais de deslocamento de pontos determinados, a partir do programa Ncorr que utiliza uma plataforma dentro do MATLAB, como se pode observar na Figura 2.

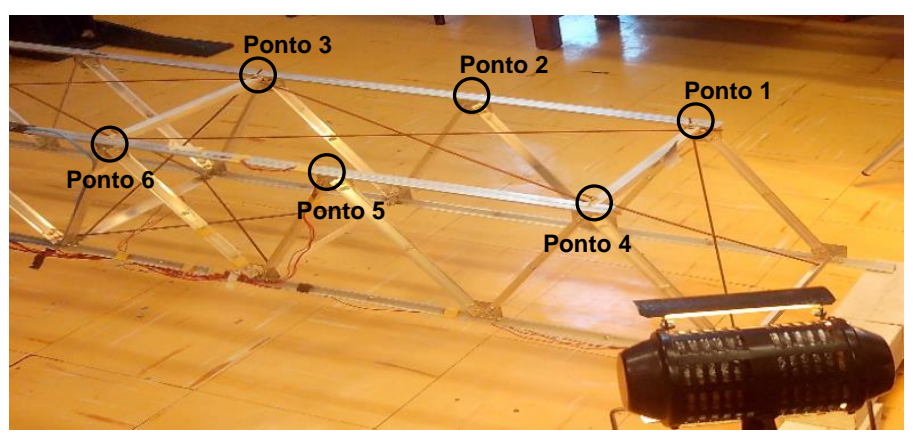

Figura 1. Ponte de alumínio ensaiada.

Com o campo de deslocamento obtido, utilizou-se o software ARTeMIS para a interpretação do resultado. A partir da análise SSI-UPC, determinou-se a frequência em $9,459 \mathrm{~Hz}$ e o modo de vibração da estrutura (Figura 3).

De acordo com a modelagem numérica realizada no software SAP2000, que utiliza o Método dos Elementos Finitos, a frequência esperada para essa ponte era de $9,660 \mathrm{~Hz}$. Dessa forma, a técnica CID mostrou-se satisfatória para a determinação da primeira frequência e do primeiro modo de vibração da estrutura, ao apresentar DOI: 10.19146/pibic-2016-51713 resultados próximos entre a modelagem numérica e os ensaios realizados em laboratório, que foram manuseados utilizando-se instrumentos comuns de baixo custo, sem especificidade técnica.

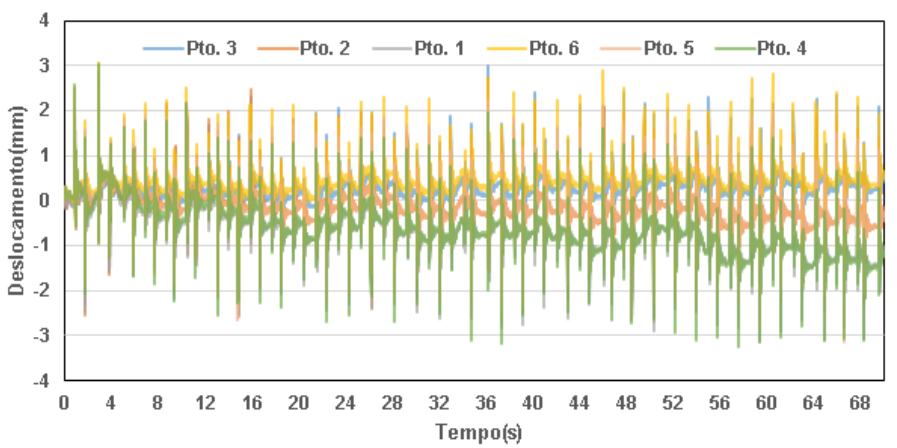

Figura 2. Campos de deslocamento da ponte de alumínio.

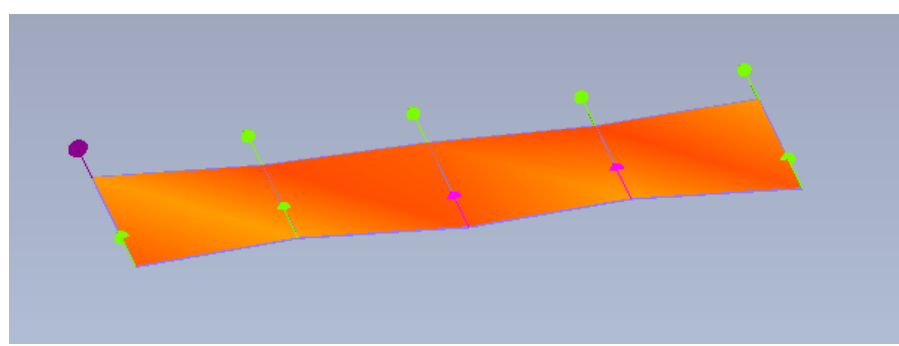

Figura 3. Análise SSI-UPC no programa ARTeMIS para o primeiro modo de vibração da ponte de alumínio.

\section{Conclusões}

Mesmo utilizando-se uma aparelhagem comum para obtenção dos dados em laboratório, os resultados utilizando a técnica CID foram satisfatórios. Dessa forma, a técnica pode ser considerada eficiente para a obtenção de propriedades dinâmicas de uma estrutura de pequeno porte nesse caso, devendo ser estudada sua verificação em outros contextos.

\section{Agradecimentos}

Agradecimentos ao Conselho Nacional de Desenvolvimento Científico e Tecnológico, à Universidade Estadual de Campinas, aos Orientadores e aos Colegas do grupo de IC pela ajuda e pelo apoio.

${ }^{1}$ Sutton, M.A.; Walters, W.J.; Peters W.H.; Ranson, W.F.; McNeill, S.R Computer vision determination of displacement using an improved digital correlation method. Image and Vision Computing, vol. 1(3), p. 133-139, 1983. 